\title{
Exploring the Short-scale Spatial Variability of Calcic Red Latosol Soil Using DUALEM-1S Proximal Soil Sensor
}

\author{
R.A.A.S. Rathnayaka and W.A.U. Vitharana ${ }^{1^{*}}$ \\ Postgraduate Institute of Agriculture \\ University of Peradeniya \\ Sri Lanka
}

\begin{abstract}
Short-scale spatial variability of soil properties need to be identified for the proper management of soil resources for crop production. Proximally sensing of soil apparent electrical conductivity (ECa) and the application of inversion technique are highly potential approaches to predict the spatial variability of soil properties. This study was carried out to investigate the applicability of ECa data together with inversion technique to predict the spatial variability of soil variability in Calcic Red Latosols. DUALEM-1S sensor was used to perform the ECa survey in an agricultural land (3.2 ha) situated in Allaveddy in the Jaffna district. The acquired ECa data were used to predict ECa at $20 \mathrm{~cm}$ depth increments down to $80 \mathrm{~cm}$ soil depth. Exploratory data analyses and then local kriging procedure were applied separately for original and inverted ECa data to construct continuous maps. Soil samples were taken from six sample points (at $20 \mathrm{~cm}$ depth intervals upto $80 \mathrm{~cm}$ from each sample point) using the purposive sampling scheme. Soil samples were analyzed for soil texture, organic matter, electrical conductivity (EC) and $\mathrm{pH}$. Proximally sensed ECaPRP $(\mathrm{CV}=45.4 \%)$ and ECaHCP $(\mathrm{CV}=73.5 \%)$ and the depth profiles of different soil properties showed a high vertical and horizontal spatial variability of soil in the site. High correlations were shown between EC (measured at different depths) and both ECaPRP $(r>0.60)$ and ECaHCP $(r>0.60)$ at different depths. However, ECa did not show strong correlations with other soil properties. The high correlations $(r>0.76)$ between depth specific inverted ECaPRP and ECaHCP measurements and measured EC of respective depths indicated that these ECa data layers can be used to map the soil salinity development in different soil layers. This study revealed a strong short-scale spatial variability of soil properties in the selected Calcic Red Latosol and proximal soil sensing using the DUALEM$1 S$ sensor is a highly potential tool for producing three dimensional maps of the soil EC.
\end{abstract}

Keywords: Apparent electrical conductivity, proximal soil sensing, short-scale spatial variability

\section{INTRODUCTION}

The short-scale spatial variability of soil properties such as soil depth, soil texture and organic carbon is a common phenomenon. The variability of these soil properties influence the soil physical, chemical and biological processes those determine the plant growth. Importantly, soil variability in both, horizontal and vertical directions are equally important in deciding the suitability of a soil for plant growth and thus its management for optimal crop

1 Department of Soil Science, Faculty of Agriculture, University of Peradeniya, Sri Lanka

* Corresponding author: uvithara@pdn.ac.lk 
production. Therefore, areas having unique combination of vertical patterns of soil properties would serve as uniform land units having different production potentials. Moreover, efficient use of agricultural inputs such as fertilizers and liming materials could be improved by changing the application rates site-specifically based on the variability of soil properties (Winehold and Doran, 2008). The traditional approach to investigate spatial variability of the soil properties is the soil spatial sampling and laboratory analyses followed by mapping, which require high inputs of labour, more time and money. The proximally sensed apparent electrical conductivity (ECa) can be considered as one of efficient, cost-effective and modern approaches to characterize the natural spatial patters of inherent soil properties (Lesch et al., 1995). Proximal soil sensors are used for measuring ECa. Among the available methods, electromagnetic induction (EMI) based methods are becoming more popular among soil surveyors due to their non-destructive nature, rapid response and ease of integration into a mobile platform for obtaining on-the-go measurements. Although the proximally sensed ECa has been used as a reliable tool to predict the horizontal spatial variability of topsoil properties such as clay (Williams and Hoey, 1987), organic matter (Jaynes et al., 1996), ECe (Rhoades and Corwin, 1992) and CEC (McBride et al., 1990) etc., the patterns of ECa at deeper layers and its relationship with soil properties have been investigated very rarely due to the lack of suitable algorithms to extract ECa in deeper layers using inversion techniques (Santos et al., 2011). However, high potential of the EMI based ECa measurements to provide quantitative estimates of the subsoil ECa at different depths have been revealed through ECa data combined with the newly developed inversion techniques (Piikki et al., 2013). EM4SOIL (EMTOMO LDA) is one such software used to invert the proximally sensed ECa acquired from proximal soil sensor (Triantafilis and Santos, 2013). The estimates of ECa are generated by the software for different depths and can be used as secondary information to predict the patterns of soil properties at respective depths. The potential of proximally sensed ECa data of soil of intermediate zone of Sri Lanka to predict the shortscale spatial variability of the different topsoil properties (soil texture, available $\mathrm{P}, \mathrm{Ca}, \mathrm{Mg}$, $\mathrm{K}, \mathrm{Na}$ ) has been investigated recently (Balasooriya et al., 2014; Rathnayaka et al., 2014), but the potential use of inverted ECa to predict subsoil properties has not been investigated so far.

Red Latosol (Typic Ustipsamments) is the most dominant soil great group distributed in the Jaffna peninsula which is extensively used for the agriculture (Mapa et al., 2010). Except few studies (Ketheeshwaren, 2005) less attention has been given for the spatial characterization of red latosols. Moreover, potential of using novel technologies such as proximal soil sensing in spatial characterization of this soil have not been investigated for Red Latosols. The applicability of proximally sensed data to predict subsoil properties become a very important research area related to optimization of the efficient use of agricultural inputs. The objective of this study was to investigate the potential of using the proximal soil sensing technique for the characterization of short-scale soil variability of red latosol at different depth intervals.

\section{METHODOLOGY}

An agricultural field (3.2 ha) located at Allaveddy in Jaffna district of Sri Lanka (20 m elevation, $9^{\circ} 47^{\prime} 12.8^{\prime \prime} \mathrm{N}, 80^{\circ} 0^{\prime} 32.21^{\prime \prime} \mathrm{E}$ ) was selected for the study (Figure 1). The study field is located in the upper position of the soil catena and Red Calcic Latosol is the dominant great soil group (Panabokke, 1996). Onion is the commonly cultivated crop in the selected agricultural field. 
DUALEM-1S (Dualem Inc) proximal soil sensor was used to perform the ECa survey. It is one of very popular second generation EMI based proximal sensors which consists of one transmitter coil (Tx) and two receiver coils ( $\mathrm{Rx})$ spaced at $1 \mathrm{~m}$. The transmitter coil and one of the receivers in the pair have horizontal coil windings and these components form the horizontal co-planar geometry (HCP). The other receiver in the pair has vertical coil windings. It combines with the transmitter to form the perpendicular coplanar geometry (PRP). The Tx is energized from an alternating current $(9 \mathrm{kHz})$ and it produces a primary magnetic field around the Tx. This primary magnetic field induces small alternating current in the soil which induces a proportionate secondary magnetic field in the soil. This induced magnetic field is superimposed on the primary field and both are measured by two receiver coils (Saey et al., 2009). Thus, the DUALEM-1S soil sensor measures two ECa values as perpendicular coplanar ECa (ECaPRP) and horizontal coplanar ECa (ECaHCP) simultaneously. Perpendicular coplanar ECa is highly sensitive to the conductivity of the topsoil, whereas ECaHCP is highly sensitive to the conductivity of the subsoil (DUALEM1S user manual, 2012). Therefore, the sensor gives provision for the investigation of soil properties at both topsoil and subsoil.

The DUALEM-1S was attached to a wooden sled and pulled at a speed approximately 3.5 $\mathrm{kmh}^{-1}$ along parallel lines spaced at $2 \mathrm{~m}$. The field computer attached to the sensor recorded $\mathrm{ECa}$ at 1 second time intervals. Thus, ECa measurements were taken at a density of $2 \mathrm{~m} \mathrm{x}$ $2 \mathrm{~m}$. Exploratory data analysis was performed separately for ECaHCP and ECaPRP measurements. Local kriging interpolation procedure was used to interpolate $\mathrm{ECa}$ data using VESPER 1.6 software. The local kriging process calculates variograms for each interpolation search window assuring a best liner interpolation of data measured at high density (Sun et al., 2010). The raster maps showing the spatial variability of ECaHCP and ECaPRP were developed using ArcGIS 10.3 software. The smaller area of the study field was selected for the investigation of the spatial patterns of the selected soil properties in relation to the ECa patterns. The sample points were spatially selected by adopting purposive sampling (Bianchini and Mallarino, 2002) approach (Figure1). Thus, comprehensive spatial representation ECa patterns was achieved.

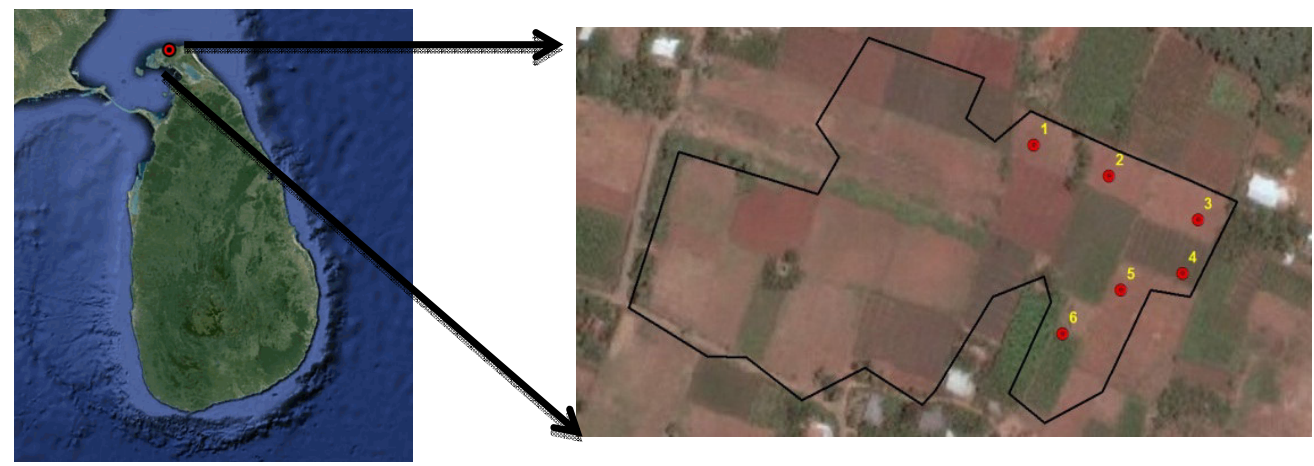

Fig. 1. The location of study field in Sri Lankan map and the satellite image showing spatial distribution of study field boundary and sample points

Soil samples were collected from each sample point at $20 \mathrm{~cm}$ depth increments down to 80 $\mathrm{cm}$ depth. The samples were air-dried and passed through $2 \mathrm{~mm}$ sieve to separate gravel, and analyzed for the soil texture, soil organic matter, $\mathrm{pH}$ and EC. Soil texture determination was 
done using the pipette method (Gee and Or, 2002). The procedure proposed by Walkley and Black (1934) was used for the determination of soil organic matter (OM\%). Soil $\mathrm{pH}$ and EC of each soil sample were determined separately in 1:2.5 and 1:5 soil/water suspensions respectively, using an $\mathrm{EC}$ meter (Eutech COND $6+$ ) and $\mathrm{pH}$ meter (Eutech $\mathrm{pH} 700$ ) to measure $\mathrm{EC}$ and $\mathrm{pH}$.

The depth profiles of clay $\%$, sand $\%, \mathrm{OM} \%$, pH and EC developed for each sample point were used to investigate the vertical spatial variability of the selected soil properties.

The depth response curves of the ECaHCP and ECaPRP models are provided in Figure 2 and these measurements provide values of ECa by integrating conductivities of thin layers of the soil. EM4SOIL inversion software (EMTOMO LDA) was used to invert ECaHCP and ECaPRP to obtain ECa of the soil depths of 20, 40, 60 and $80 \mathrm{~cm}$. The exploratory data analysis was separately done for inverted ECa data set obtained for different depths.

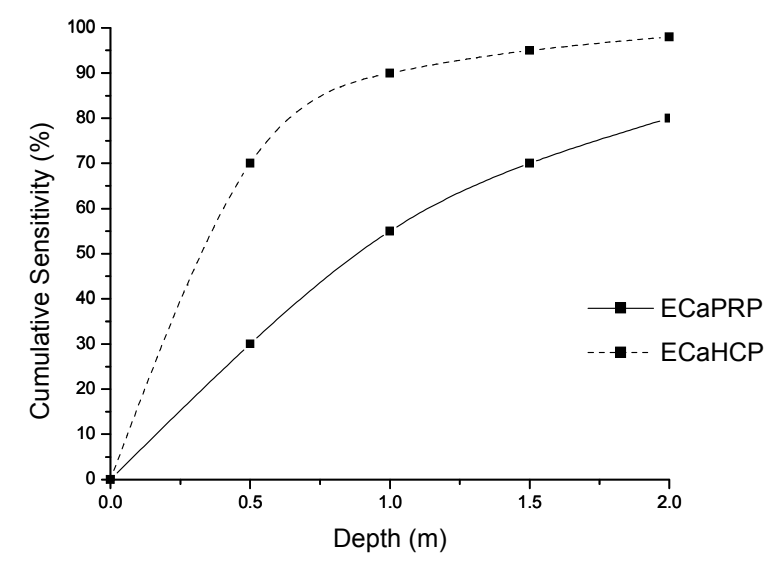

Fig. 2. The cumulative sensitivity in percentage of ECaPRP and ECaHCP for the different depths of soil

Local kriging procedure was performed to interpolate ECa data estimated through inversion technique using VESPER 1.6 software. The interpolated ECa data, estimated through inversion were used to develop maps showing the spatial variability of $\mathrm{ECa}$ at different depths. ArcGIS 10.3 software was used to prepare maps. The ECa of each sample location at four depths were extracted from the corresponding interpolated maps using ArcGIS 10.3 software. The applicability of the original and estimated ECa produced by inversion to predict the patterns of inherent soil properties were determined considering the correlations between measurements of different soil properties and respective original and inverted ECa data extracted from the sample location at different depth. 


\section{RESULTS AND DISCUSSION}

\section{Variability of proximal sensor measured ECaHCP and ECaPRP}

The ECa surveys followed by exploratory data analysis resulted in 5884 ECaPRP and 5890 ECaHCP point measurements. Table.1 shows the summary statistics of the apparent electrical conductivity (ECa) measured with DUALEM-1S sensor.

ECaPRP measurements ranged from $6.1 \mathrm{mSm}^{-1}$ to $67.7 \mathrm{mSm}^{-1}$ with the mean of $25.07 \mathrm{mSm}^{-1}$ and the coefficient of variation $(\mathrm{CV})$ of $45.35 \%$ while ECaHCP measurements ranged from $-12.4 \mathrm{mSm}^{-1}$ to $37.39 \mathrm{mSm}^{-1}$ with the mean of $11.73 \mathrm{mSm}^{-1}$ and the $\mathrm{CV}$ of $73.49 \%$. Moreover, ECaPRP had moderate variability (between 12\% and 60\%) and ECaHCP had high variability $(>60 \%)$ according to the classification of CV by Warrick and Nielsen (1980). The coefficients of skewness and kurtosis of each ECa data type indicate that both the distributions are positively skewed and platykurtic.

DUALEM-1S sensor usually gives positive values as proximally sensed ECa values for soil. Apparent electrical conductivity measures the ability of solid and solution phases in soil to transmit an electrical current. The charged colloids such as clay and humic substances highly contribute to the ECa from soil solid phase, while dissolved ions contribute to ECa from soil solution phase (Ristolainen et al., 2009). The sensor provided negative values as proximally sensed ECaHCP for some locations. Moreover, those negative values were concentrated to five specific areas in the study field. The negative values for proximally sensed ECa for soil are usually resulted by the sensor when it is oriented perpendicular to a high conductive buried objects such as iron or steel in soil (Stanton and Schrader, 2001). Therefore, it revealed that the spatial variability of the conductivity of studied soil has been altered by the anthropogenic activities

Table1. Statistical parameters of ECaHCP and ECaPRP measurements proximally sensed using DUALEM-1S sensor

\begin{tabular}{lllllllll}
\hline Variable & N & Min. & Max. & Mean & SD & CV & Skewness & Kurtosis \\
\hline ECaPRP $\left(\mathrm{mSm}^{-1}\right)$ & 5890 & 6.1 & 67.7 & 25.07 & 11.37 & 45.35 & 0.539 & -0.119 \\
ECaHCP $\left(\mathrm{mSm}^{-1}\right)$ & 5884 & -12.4 & 37.9 & 11.73 & 8.62 & 73.49 & 0.173 & 0.048 \\
\hline
\end{tabular}

Maps of both ECaPRP and ECaHCP, produced through local kriging procedure showed identifiable short-scale spatial variability in the study field (Figure 3). The pattern of ECaPRP and ECaHCP are different from each other implying differences in spatial variability of conductivity at topsoil and subsoil or vertical heterogeneity of soil conductivity. 
a)

\section{Spatial variability of ECaPRP}

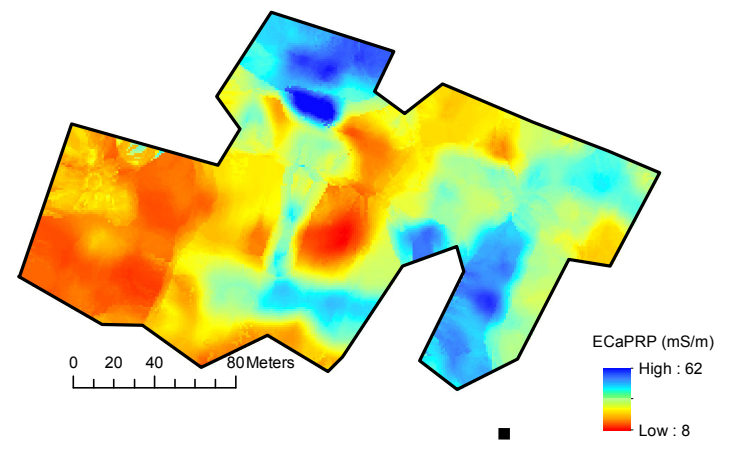

b) Spatial variability of ECaHCP

Fig. 3. Maps showing the spatial variability of the proximally sensed (a) ECaPRP and (b) ECaHCP

\section{Variability of soil properties in vertical and horizontal directions}

The depth profiles developed for individual soil properties showed a vertical spatial variability of each sampling point (Figure 4a-4e). Depth profiles indicated considerable variability of all properties at different depth intervals. The surface soil clay content $(0-20$ $\mathrm{cm}$ ) ranged from $8 \%$ to $30 \%$ across sample points. This variability increased as the depth increases. According to the USDA classification, subsurface layers with a significantly higher percentage of phyllosillicate clay (1.2 times or more than clay percentage in elluvial horizon) overlying soil materials are known as argillic horizon (USDA survey staff, 2014). All the profiles showed the evidence of presence of argillic horizons. However, the argillic horizon occurring depth differs from one sample point to another. The clay profiles of sample locations 2, 5 and 6 showed a presence of argillic horizons at depth of 40-60 cm whereas, those of sample locations of 3 and 4 exhibited argillic horizons from $60 \mathrm{~cm}$ onwards upto $80 \mathrm{~cm}$ or more. Moreover, the presence of argillic horizon of sample point 1 could be seen from 20-60 cm. Huang et al. (2011) have showed some limitations to crop growth in the presence of argillic horizon such as poor drainage with purched water table and acting as a barrier to the root penetration. The main possible reason for increasing clay content at deeper layers is due to the translocation (elluviations) of clay particles from surface horizon and deposition in subsurface horizons (Kozlovskii et al., 2001). The profile diagrams (Figure 4a) showed variation of the elluviations and illuviation processes at six sample locations and consequently larger variability of clay content in deeper horizons. The $\%$ OM content of the top soil layer ranged between 1.2-6.6\% (Figure 4c). The depth profiles showed accumulation of $\mathrm{OM}$ in the surface layer. Rusco et al. (2001) stated that accumulation of OM mainly occurs in the surface horizon due the continuous input of plant biomass and high activity of soil microorganisms. 
Clay \%
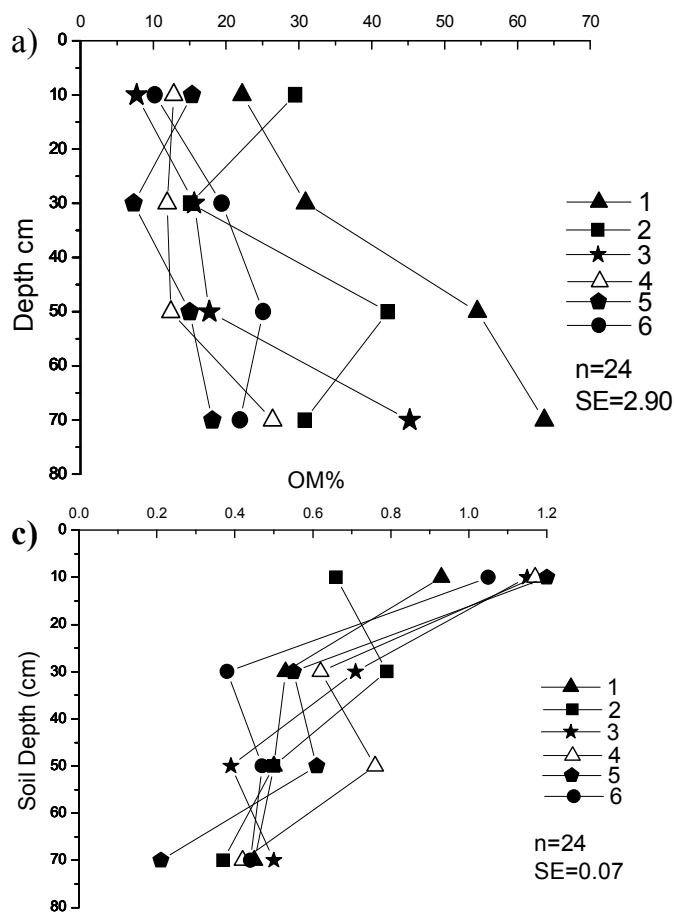

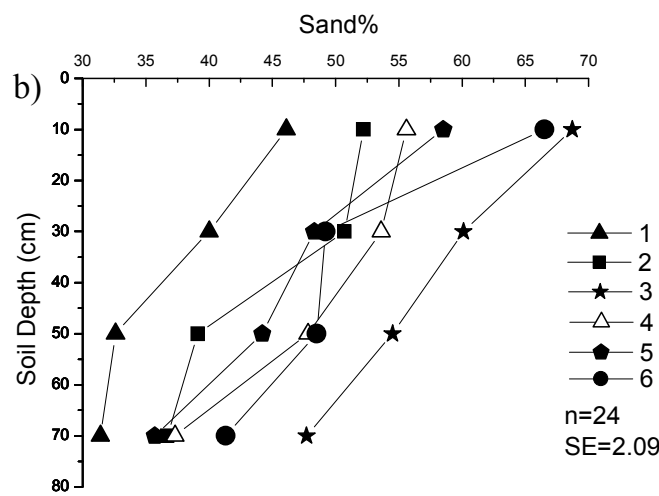

$\mathrm{pH}$

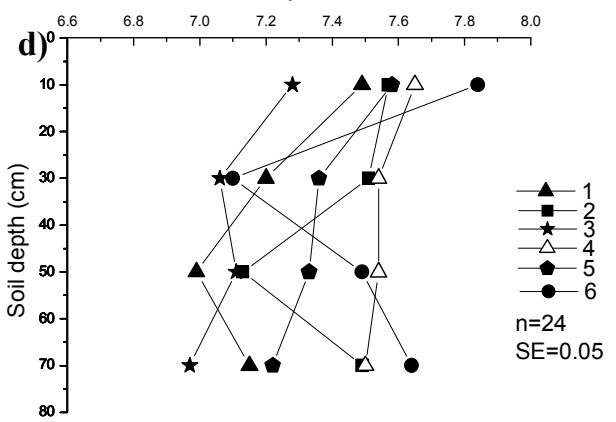

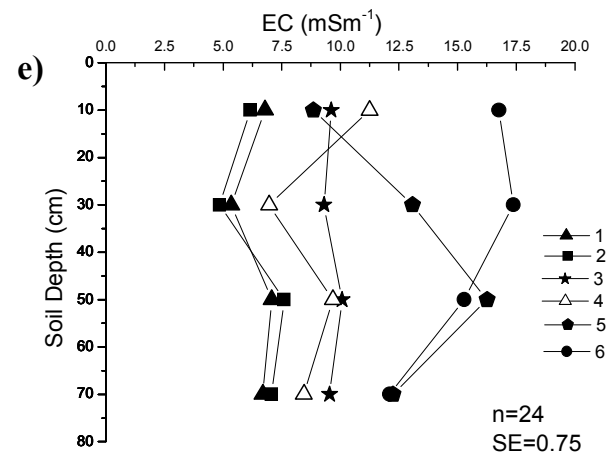

Fig. 4. The depth profiles of (a) clay\%, (b) sand\%, (c) OM\%, (d) pH and (e) EC

Soil pH (Figure 4d) showed a moderate variability within the surface soil (7.3-7.8). This did not change drastically along vertical direction of the soil. According to soil $\mathrm{pH}$ classification by Hornek et al. (2011), $\mathrm{pH}$ values of all the layers at each sample point were within the range of neutral or moderately alkaline. Calcic Red Latosol is a type of Red Latosol, developing on the marine sediments, near to the coastal area (Panabokke, 1996). Marine sediments are rich in $\mathrm{CaCO}_{3}$. Thus, the resultant Red Calcic Latosol soil is also composed of high amount of $\mathrm{CaCO}_{3}$. This would lead to an increase of soil $\mathrm{pH}$ throughout the soil profile. Soil EC of the surface soil (Figure 4e) showed a considerable variability $\left(5-17.5 \mathrm{mSm}^{-1}\right)$. However, this variability narrowed at deeper soil layer $(60-80 \mathrm{~cm})$. All EC profiles except sampling points 5 and 6 showed small variation along the depth. The EC profiles of sample 
point 5 and 6 showed large variation along the depth. The EC depth profiles of most of the sample locations showed comparatively higher values at surface soil layer and deeper soil layers, while lower EC in middle most layers. The water evaporation followed by accumulation of dissolved salts continuously at surface layer due to high temperature in the area, may be the reason for high EC in surface layer. The leaching of the dissolved salts from middle most layers to the deeper layers may be the reason for lower EC in deeper layers.

\section{Relationships between proximal sensed ECa and soil properties}

The measurements of ECaHCP and ECaPRP were highly correlated with the measured EC at different depths (Table 2). Moreover, EC measured at 0-20 cm, 20-40 cm and 40-60 cm showed stronger correlations with ECaPRP than ECaHCP. This proved a representation of the conductivity of surface and subsurface layers by ECaPRP measurement. The cumulative response curve of ECaPRP (Figure 2) shows that $75 \%$ of its response is attributed to the soil layer $0-60 \mathrm{~cm}$. In contrast, soil EC measured at $60-80 \mathrm{~cm}$ showed a strong correlation with ECaHCP which is more sensitive for deeper soil layers (Table 2). However, most soil properties such as OM\% $(\mathrm{r}<0.59)$, $\mathrm{pH}(\mathrm{r}<0.33)$ and sand\% $(\mathrm{r}>-0.59)$ showed poor to moderate correlations with both ECaPRP and ECaHCP. Proximally sensed ECa measurements have shown strong positive correlations with OM\% (Jaynes et al., 1994), clay\% (Williams and Hoey, 1987), CEC (McBride et al., 1990) in non-saline soil. In saline soils, ECa measurements have shown a strong positive correlation with the electrical conductivity of the soil solution (Rhoades and Corwin, 1992). Although, the selected field is not saline, the proximal sensed ECa showed a strong correlation with the EC of soil solution. Moreover, as indicated by Amexketa (2007), strong positive correlations between ECa measurement and other soil properties can be masked by the soil electrical conductivity being the major factor contributing to the measured ECa values.

Table 2. Correlation coefficients of measured EC with ECa extracted from interpolated ECa maps (both ECaHCP and ECaPRP) and depth specific inverted ECa from corresponding interpolated inverted ECa maps at sampling point

\begin{tabular}{lllll}
\hline & \multicolumn{4}{c}{ EC measurements $\left(\mathbf{m S m}^{-\mathbf{1}}\right)$} \\
\hline & $\mathbf{( 0 - 2 0 c m})$ & $\mathbf{( 2 0 - 4 0 c m )}$ & $\mathbf{( 4 0 - 6 0 c m )}$ & $\mathbf{( 6 0 - 8 0 c m )}$ \\
\hline ECaPRP & 0.724 & 0.848 & 0.596 & 0.728 \\
\hline ECaHCP & 0.601 & 0.792 & 0.592 & 0.770 \\
\hline Depth specific inverted & 0.809 & 0.913 & 0.762 & 0.777
\end{tabular}

The results of the exploratory data analysis of ECa data at different depths are given in Table 3 . The predicted ECa at $10 \mathrm{~cm}, 30 \mathrm{~cm}$ and $50 \mathrm{~cm}$ showed a moderate spatial variability (12$60 \%)$ and the predicted ECa at $70 \mathrm{~cm}$ showed high spatial variability $(>60 \%)$ according to classification of CV proposed by Warrick and Nielsen (1980). The predicted ECa at depths of both $10 \mathrm{~cm}$ and $30 \mathrm{~cm}$ are almost the same. All the distributions of predicted ECa of different depths are positively skewed and platykurtic. 
Table 3. Summary statistics for the predicted ECa $\left(\mathrm{mSm}^{-1}\right)$ for different depth using inversion technique of EM4SOIL Inversion software

\begin{tabular}{lllllllll}
\hline Variable & N & Min. & Max. & Mean & SD & CV & Skewness & Kurtosis \\
\hline $\mathrm{ECa}(10 \mathrm{~cm})$ & 2430 & 10 & 99.5 & 38.98 & 17.57 & 45.07 & 0.320 & -0.658 \\
$\mathrm{ECa}(30 \mathrm{~cm})$ & 2430 & 10 & 99.5 & 38.98 & 17.57 & 45.07 & 0.320 & -0.658 \\
$\mathrm{ECa}(50 \mathrm{~cm})$ & 2430 & 22 & 68.9 & 26.20 & 12.29 & 46.91 & 0.435 & -0.381 \\
$\mathrm{ECa}(70 \mathrm{~cm})$ & 2430 & 1.4 & 38.5 & 10.75 & 7.22 & 67.16 & 1.027 & 1.370 \\
\hline
\end{tabular}

The interpolated maps showing the spatial variability of ECa for different depths are given in the Figure 5. The patterns of spatial variability of all the maps are slightly different from one to another. However, the coefficient of variation for the inverted $\mathrm{ECa}$ has increased with the depth. It proved that deeper layers have inverted ECa with high variability due to smaller population means and relatively high standard deviations.

a)

Spatial variability of predicted ECa at the depth of $20 \mathrm{~cm}$

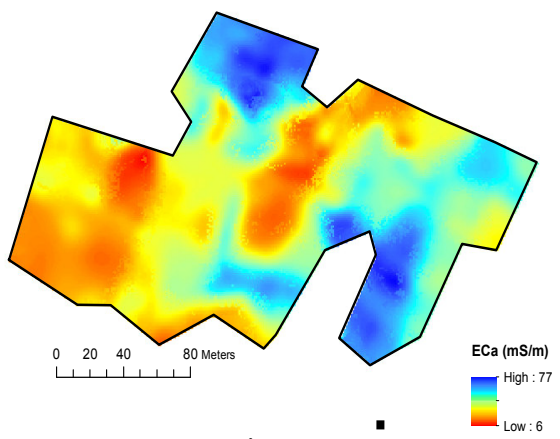

c)

Spatial variability of predicted ECa at the depth of $60 \mathrm{~cm}$

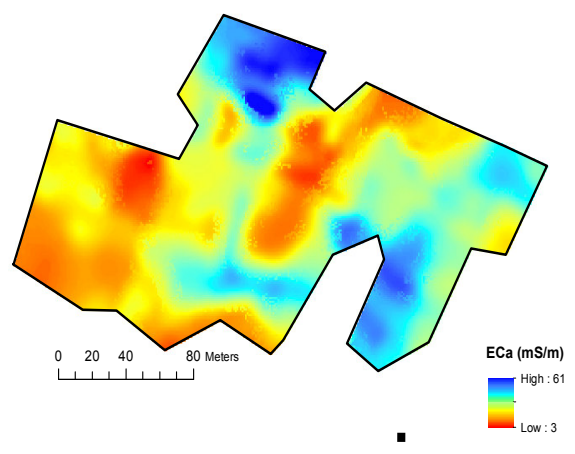

b)

Spatial Variability of predicted ECa at the depth of $40 \mathrm{~cm}$

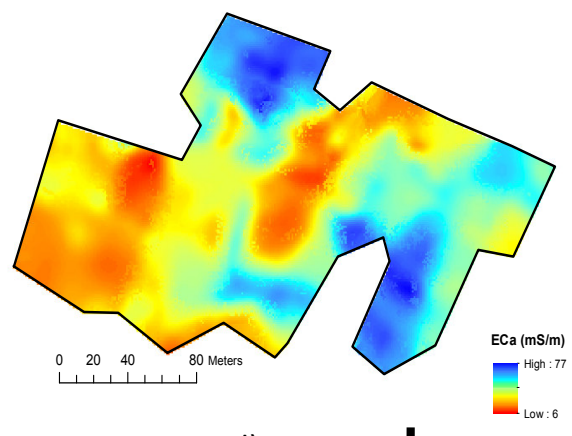

d)

Spatial variability of predicted ECa at the depth of $80 \mathrm{~cm}$

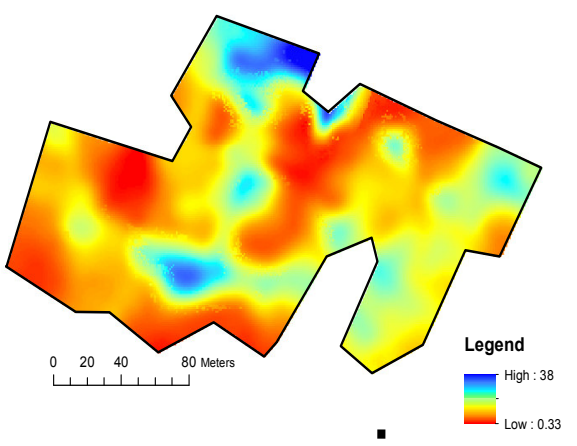

Fig. 5. The maps showing the spatial variability of ECa predicted by inversion technique at the depth of (a) $20 \mathrm{~cm}$, (b) $40 \mathrm{~cm}$, (c) $60 \mathrm{~cm}$ and (d) $80 \mathrm{~cm}$

The inverted ECa data at four depths showed strong correlations with corresponding EC (Table 2). The soil EC measurements showed a stronger correlation with estimated inverted 
ECa than either ECaHCP or ECaPRP proving that relationships between sensor measured $\mathrm{ECa}$ and soil properties can be strengthened through the data inversion. However, inverted ECa data at four depths showed unexpected very poor correlations with other measured soil properties such as OM\% $(\mathrm{r}<0.36)$, clay\% $(\mathrm{r}<-0.31)$, sand $\%(\mathrm{r}>0.35)$, and $\mathrm{pH}(\mathrm{r}<0.43)$.

\section{CONCLUSION}

The proximal soil sensing revealed a strong spatial heterogeneity of apparent electrical conductivity of both in the surface and subsurface horizons of the calcic red latosol soil. Investigation of clay, sand, silt, $\mathrm{OM} \%, \mathrm{pH}$ and soil solution $\mathrm{EC}$ at four depth intervals at five sampling locations showed a strong variability of these soil properties in both vertical and horizontal directions. In Calcic Red Latosols, considerable variability of soil properties at short-scale can be expected. The prediction of soil properties such as Clay\%, Sand\%, OM\% and $\mathrm{pH}$ by proximally sensed ECa have been concealed due to the dominant influence of soil solution EC. The overall results suggest that the proximal soil sensing has a high potential of mapping the salinity development in the calcic red Latosols in the Jaffna peninsula. The calculation of depth specific ECa by inverting ECaPRP and ECaHCP measurements indicated that these ECa data layers can be used to map the soil salinity development in different soil layers. Thus, proximal soil sensing using the DUALEM-1S sensor can be considered to be a highly potential tool for producing three dimensional maps of soil salinity in the Calcic Red Latosols.

\section{REFERENCES}

Amezketa, E. (2007). Soil salinity assessment using directed soil sampling from a geophysical survey with electromagnetic technology. Spanish Journal of Agricultural Research. 5(1), 91 - 101.

Anonymous. (2012). DUALEM-1S with GPS User's Manual. DUALEM Inc., 540 Churchill Ave, Milton, ON Canada.

Balasooriya, W.K., Rathnayaka, R.A.A.S., Vitharana, W.A.U., Thilakarathna E.M.S.K, Verdoodt A., Saey, T. and Van Meirvenne M. (2014). Apparent Electrical Conductivity $\left(\mathrm{EC}_{\mathrm{a}}\right)$ based potential management zones for site specific nutrient management in paddy soils of Sri Lanka. Proceeding of $20^{\text {th }}$ world Congress in Soil Science. June 2014, Korea.

Biachini, A.A. and Mallarino A.P. (2002). Soil-sampling alternatives and variable-rate liming for a soybean-corn rotation. Agronomy Journal. 94, 1355 - 1366.

Gee, W. G. and Or, D. (2002). Particle size separation. In Jacob, H. Dane, G. Clarke Topp, and Warren A Dick, Method of soil analysis: part 4 physical methods. WI: Soil Science Society of America, Inc Madism.

Hauang, P.M., Li, Y. and Sumner M.E. (2011). Hand book of soil science: properties and processes ( $2^{\text {nd }}$ edition). CRC press.

Horneck, D.A., Sullivan, D.M., Owen, J.S. and Hart, J.M. (2011). Soil Test Interpretation Guide (EM 1478). OSU Extension Catalog. 
Jaynes, D.B., Novak, J.M., Moorman, T.B. and Cambardella, C.A. (1996). Estimating herbicide partition coefficient from electromagnetic induction measurements. Journal of environmental quality. 54, $36-41$.

Ketheeshwaren, S. (2005). Preliminary study of the electrical characterization of Red-Yellow latosols in Viligaman. MSc thesis. Department of Physics, Faculty of Science, University of Jaffna, Sri Lanka.

Kozlovskii, F.I., Rühlmann, J., Travnikova, L.S. and KuzyakovYa. V. (2001). Clay Differentiation in Initially Homogeneous Substrates upon Long-term Field Experiments. Eurasian Soil Science. 34(2), 130 - 138.

Lesch, S.M., Strauss, D.J. and Rhoades, D.J. (1995). Spatial prediction of soil salinity using electromagnetic induction techniques: An efficient spatial sampling algorithm sustainable for multiple linear regression model identification and estimation, Water Resources Research. $31,3387-3398$.

Mapa, R.B., Somasiri, S. and Dassanayake, A.R. (2010). Soils of the Dry Zone of Sri Lanka. Special Publication No.7, Soil Science Society of Sri Lanka.

McBride, R.A., Gordon, A.M. and Shrive S.C. (1990). Estimating forest soil quality from terrain measurements of apparent electrical conductivity. Soil Science Society America journal. 54, 290 - 293.

Panabokke, C.R. (1996). Soil and Agro-Ecological Environments of Sri Lanka. Natural Resources, Energy and Science Authority, 47/5, Maitland Place, Colombo 7, Sri Lanka.

Piikki, K., Soderstrom, M., Wetterlind, J. and Stenberg, B. (2013). Three layered maps based on sensor measurements. pp. 33-35. In: Stafford (Ed.), J.V. Precision Agriculture'13. Wageningen Acedemic publisher, Netherland.

Rathnayaka, R.A.A.S., Vitharana, U.W.A., Van Meirvenne, M. And Verdoodt, A. (2014). Detailed mapping of soil texture using proximally sensed apperent electrical conductivity. Proceeding of the University of Peradeniya International Researh Sessions. 18. 453.

Rhoades, J.D. and Corwin, D.L. (1992). Determining soil electrical conductivity-depth relations using an inductive electromagnetic conductive meter. Soil Science society America Journal. 45, 255 - 260.

Ristolainen, A., Farkas, C. and Toth, T. (2009). Prediction of soil properties with field geoelectrical probes. Communications in soil science and plant analysis. 40, 555 - 565.

Rusco, E., Jones, R. and Bidoglio, G. (2001). Organic matter in soils of Europe. European soil bureau. Soil and waste unit, Institute for environment and sustainability, JRC Ispra.

Saey, T., Simpson, D., Vermeersh, H., Cockx, L. and Van Meirvenne, M. (2009). Comparing the EM38DD and DUALEM-21S sensors for depth-to-clay mapping, Soil Science Society of America. 73(1), 7 - 12. 
Santos, F.A.M., Triantafilis, J. and Bruzgulis, K. (2011). A spatially constrained 1D inversion algorithm for quasi-3D conductivity imaging: Application to DUALEM-421 data collected in a riverine plain. Geophysics. $76 B, 44-53$.

Stanton, G.P. and Schrader, T.P. (2001). Surface Geophysical Investigation of a Chemical Waste Landfill in Northwestern Arkansas. In: Kuniansky, E.L. (Ed.) U.S. Geological Survey Karst Interest Group Proceedings, Water-Resources Investigations Report 01-4011.

Sun, W., Minasny, B. and McBratney, A. (2010). Local regression Kriging approach for analyzing high density data. $19^{\text {th }}$ World Congress of Soil Science, Soil Solutions for a Changing World. Brisbane, Australia.

Triantafilis, J. and Santos, F.A.M. (2013). Electromagnetic conductivity imaging (EMCI) of soil using a DUALEM-421 and inversion modelling software (EM4Soil). Geoderma, 211$212,28-38$.

USDA survey staff. (2014). Keys to soil taxonomy Twelfth edition. United State Department of Agriculture, Natural Resource conservation service.

Walkley, A. and Black, I.A. (1934). An examination of the Degtjareff method for determining soil organic matter and a proposed modification of the chromic titration method. Soil Science. 37, 29 - 38.

Warrick, A.W. and Nielsen, D.R. (1980). Spatial variability of soil physical properties in the field. In: Hillel, D. (Ed.) Applications of Soil Physics, Academic Press, New York, NY, USA.

Wienhold, B.J. and Doran, J.W. (2008). Apparent electrical conductivity for delineating spatial variability in soil properties. In: Allered, B.J., Daniels, J.J. and Ehsani, M.R. (Ed.) Handbook of Agricultural Geophysics, CRC, BBS.

William, B. and Hoey, D. (1987). The Use of Electromagnetic Induction to detect the spatial variability of salt and clay content of soils. Australian Journal of Soil Research. 25, 21 - 27. 